\title{
Binomios en la enseñanza musical
}

\author{
Resonancias desde la formación \\ de docentes de educación general
}

Lía Zilli

[Universidad Nacional del Litoral]

Emanuel Ferrero

[Universidad Nacional del Litoral]

Resumen En el presente artículo reflexionaremos en torno a los relatos de tres docentes de música que actualmente se desempeñan en institutos de formación de docentes (IFD) en la ciudad de Santa Fe*.

Recuperaremos parte de lo dicho en tres binomios: Escuchar-Disfrutar, Arriesgar-Desarmar y Convivir-Vincular; que permitan acercarnos a la complejidad y heterogeneidad que caracterizan a las prácticas de Educación Musical (en el Nivel Superior en general y en los IFD en particular). A partir de ese acercamiento, articularemos algunas posibilidades para pensar el lugar del placer y del disfrute en su vínculo con la escucha, el riesgo como espacio de oportunidad para la transformación de prácticas docentes y el desafío de irrumpir en la enseñanza de la música desde un abordaje vincular y humano en sintonía con el convivir.

Palabras clave: enseñanza de la música . formación docente $\cdot$ nivel superior

* En los Institutos Superiores $N^{\circ} 8$ "Alte. Guillermo Brown" y № 32 "Gral. San Martín", dentro de las carreras de Profesorado de Educación Inicial, Profesorado de Educación Primaria y Profesorado de Educación Especial.
Summary This article aims to reflect upon the narratives of three music teachers who currently work in teacher training institutes (known as IFD by its initials in Spanish) in Santa Fe**. We will pick up on part of what has been said in three binomials: Listen-Enjoy; Risk-Disassemble; Coexist-Bond, which enables us to get closer to the intricacy and the diversity that characterize the Music Education practices (in higher education in general and in the IFD in particular). From this approach, we will articulate some possibilities of thinking about the place that pleasure and enjoyment occupy when tied to listening, about risk as a window of opportunity for the transformation of teaching practices and about the challenge of bursting into music teaching with a humane and bonding approach in tune with coexisting with one another.

Keywords: Music teaching .

Teacher training - University level

** In Instituto Superior n o 8 'Alte. Guillermo Brown' and Instituto Superior n. 32 'Gral. San Martín', in the Teacher Training Courses for Early Childhood Education, Primary Education and Special Education. 


\section{INTRODUCCIón}

El buen artesano, además, emplea soluciones para desvelar un territorio nuevo; en la mente del artesano, la solución y el descubrimiento de problemas están intimamente relacionados. Por esta razón, la curiosidad puede preguntar indistintamente "por qué» $y$ "cómo" acerca de cualquier proyecto

Sennett, 2009: 23

Al poco tiempo de comenzar a leer El artesano de Richard Sennett fue casi imposible que su espíritu no imprima una manera particular de tratar con el material recolectado en las entrevistas y no se cuele entre las páginas de este escrito. Tal es así que decidimos que nos acompañe en este comenzar a abrirnos camino por el mismo.

Su noción de artesano, que resonó profundamente con nuestra idea de componer un tejido o una trama, se refleja en la construcción artesanal de los tres binomios que dan cuerpo a este artículo. Ellos son: EscucharDisfrutar, Arriesgar-Desarmar y Convivir-Vincular. A partir de los mismos, articularemos nuevas posibilidades para pensar el lugar del placer y del disfrute en su vínculo con la escucha, el riesgo como espacio de oportunidad para la transformación de prácticas docentes y el desafío de irrumpir en la enseñanza de la música desde un abordaje vincular y humano en sintonía con el convivir.

Adentrémonos un poco en la naturaleza de estos binomios. «Binomio» remite a un conjunto de dos cosas tomadas como una unidad, o como elementos en equilibrio o dependientes uno de otro. Sin embargo, en este caso, más que señalar una vinculación equilibrada o de dependencia, deben entenderse como fórmulas en las que los elementos se complementan, trabajando uno sobre el otro; y que funcionan como artefactos a través de los cuales podremos captar y construir algunos sentidos ${ }^{1}$ poderosos en torno a la Educación Musical; sentidos que impacten,

1 Entendidos como "algo del orden de lo intangible, que no se materializa, se construye, se produce, se descubre en su insistencia, se captan (Deleuze en Souto, 2016: 247). 
derriben, atraviesen o conmuevan, como maneras de abordar, conocer, imaginar y poner ideas en movimiento.

Estos binomios son los dispositivos a través de los cuales interpretamos las entrevistas realizadas a tres docentes de música que se desempeñan en institutos de formación de docentes de educación general en la ciudad de Santa $\mathrm{Fe}^{2}$, llevadas a cabo de manera virtual en agosto de 2020. En ellas conversamos acerca de múltiples tópicos, tales como: sus experiencias personales en relación con la música; los aportes musicales y artísticos que nutren sus prácticas; los saberes a los que dan relevancia en las mismas; sus inquietudes o los aspectos «no explorados» que perciben en relación con la enseñanza de la música en el ámbito en el que se desempeñan; y el lugar de lo artesanal y lo humano en su hacer pedagógico-musical. Si bien constituyen relatos singulares y situados, retomaremos de ellos algunas resonancias, que dieron pie para la construcción de estos binomios.

Antes de avanzar más no queremos dejar de hacer mención de algunas otras ideas que fueron fundamentales para la construcción de este escrito. Para ello, volvamos a Sennett. El autor señala: «el buen artesano $[. .$.$] emplea soluciones para desvelar un territorio nuevo { }^{3}$ (Sennett, 2009: 23). Desvelar, casualmente, presenta una doble acepción interesante. Según la primera, sería algo así como quitar el sueño a alguien o a algo. La segunda propone que es descubrir o manifestar algo que estaba oculto. Algo de esto oculto nos remite a lo plegado o lo implicado (otras ideas claves en este artículo).

\section{$1 \cdot$ ESCUCHAR - DISFRUTAR}

A través de las voces de las docentes se fue dibujando un panorama complejo y multidimensional en relación con la escucha. Pero comencemos

2 A partir de las prácticas de educación musical que las mismas llevan a cabo dentro de los espacios curriculares Área Estético Expresiva y Taller de Expresión (que, en ambos casos, se dictan en formato taller, incluyendo "Lenguaje Musical» junto a "Lenguaje Plástico-Visual» y "Lenguaje Corporal»).

3 La cursiva es nuestra. 
por un aspecto de ella que posiblemente sea familiar para los lectores. Se trata de la misma como habilidad cognitiva, comprendida dentro de uno de los tres modos de conocer en música: la percepción ${ }^{4}$.

Para vincular este aspecto perceptivo de la escucha, aunque con la intención de ir un poco más allá, recuperemos algunos matices en voz de las docentes. La entrevistada II señala lo siguiente: «a esto de la escucha lo planteo como troncal. O sea, no hay un hacer sonoro sin antes una percepción, no solo desde la escucha, sino desde todos los sentidos». Fijemos la atención, por un lado, en la propuesta de que antes de cualquier «hacer sonoro» debe haber un trabajo sobre la percepción, que comprometería a la escucha como uno de múltiples aspectos. Este trabajo, además, debería darse «desde todos los sentidos», por lo que intuimos que percepción y acción estarían en interacción constante y mutuamente reguladas.

Por otro lado, en estrecha relación con esta percepción «desde todos los sentidos", la entrevistada III relata lo siguiente respecto a una experiencia con una alumna no vidente:

Fue todo un desafío que ella escuche las músicas no solo con los oídos, sino con su cuerpo. Que pueda moverlo, cuando escuchamos sonidos, cuando escuchamos instrumentos, cuando escuchamos una melodía. Entonces fue: «tocá mi brazo, mirá cómo hace, sentilo vos, ¿̨cómo está el tuyo?» Empezar también a leer sobre cómo trabajar esto del cuerpo en la música, con educación física y plástica, para que esta chica se suelte. [...] Yo nunca pensé que podía enseñarle a alguien a sentir con mover el cuerpo. Siempre había sido escuchar y traducir al cuerpo muy poco. Entonces ese fue un desafio que me plantee: [...] yo me decía a mí misma: «no puedo permitir que la música no la pueda sentir con el cuerpo». (Entrevistada III)

4 Siguiendo a Davidson y Scripp (1992: 7-9), la percepción (uno de los tres modos de conocer en música propuestos por los autores) tiene que ver con el reconocimiento y la discriminación de elementos musicales, dimensiones o formas y con la capacidad de realizar juicios con conocimiento desde la escucha. 
Estas palabras, portadoras de una fuerza renovadora casi indecible, provocaron un verdadero sacudón a nuestras ideas. Invitamos a los lectores a recorrer nuevamente el fragmento, con detenimiento, como si de palabras sagradas se trataran (y casi que lo son).

¿No resulta casi irrisorio y terrible que el acto de percibir la música y de vivenciarla sea desarraigado de un cuerpo que la produce y posibilita? Preocupa la idea de una enseñanza en la que los cuerpos sean disociados de los actos de aprender y de conocer en música. Esta última cita, en cambio, propone una escucha ampliada y complejizada, y da cuenta de una forma de acercarnos a ella desde la acción incluida y retroalimentada; escucha situada desde un cuerpo, desde su singularidad, que da lugar a acontecimientos ilimitados. ¡Vaya si esto no constituye un desafío para la Educación Musical!

Más tarde en la conversación, la misma docente vincula la discusión sobre la escucha con otros aspectos que refieren a singularidades y diferencias asociadas a la formación. Veamos un fragmento que puede acercarnos a algunas de las particularidades de la enseñanza de la música en los institutos de formación docente (IFD):

[En los IFD] no se da música como podríamos dar en el Instituto [Superior de Música] a quien va a estudiar música. Es otra cosa. [...] Cuando uno estudia la carrera de música no es así, uno va a estudiar los códigos, todo lo que tenemos que saber para ser músicos. En cambio, en el profesorado se ve toda la otra parte cultural, la otra parte de la experiencia, de expresión, de expresar con el cuerpo, de... como escuchar de otra manera. (Entrevistada III)

Aquí, desde nuestro asombro, no podemos más que insistir en lo siguiente: ¡cómo es posible que quien estudie música no disfrute de experiencias de escucha placentera? ¿Qué aspectos en la formación prescriben algunas formas de acceder a las escuchas como autorizadas, en detrimento de otras más sensibles o expresivas, que parecen excluidas de la misma? Lo dicho por la entrevistada sacude y moviliza, si bien no sorprende (más de uno habrá experimentado en su propia formación algu- 
nas de estas sensaciones). Deja así un sabor amargo lo privativo de esas escuchas desvinculadas de los cuerpos presentes, que aparecen en ciertos trayectos de la formación.

Pero no nos desanimemos. Se descubren, en ese fragmento, otros aspectos vinculados a la escucha mucho más alentadores. Pareciera que en los IFD en parte se enseña a (o bien «se va a») «escuchar de otra manera». Imaginemos entonces cuáles podrían ser esas otras maneras de escuchar, que parecen configurarse de manera particular en las clases de música de dichos espacios. Configuraciones que, sostenemos, permiten ir más allá de la domesticación y pasividad que muchas veces se instalan al interior de la formación en la enseñanza de la música, en relación con el escuchar.

Una de estas configuraciones tiene que ver con que en estas carreras no se «ofrece» una enseñanza especializada de la música, sino que la música forma parte de un trayecto de la formación específica en el marco de la formación docente general. ¿`Y no es allí, precisamente, donde más énfasis debe hacerse sobre el disfrute en el contacto con aquello que las músicas nos ofrecen y que el docente vuelve disponible 5 al enseñar?

Otra de esas configuraciones está vinculada a las particularidades que adopta la enseńanza de la música al realizarse en formato taller, donde el trabajo colectivo se habilita a partir de los lenguajes que conforman las cátedras. Es decir, un cuerpo junto a otros y una pluralidad de materias significantes, donde lo inteligible y lo sensible se redimensionan afectándose mutuamente en un hacer musical y artístico compartido.

Por último, destacamos también que, al evocarse en ese fragmento estas otras maneras de escuchar, podríamos intuir que hay unas maneras de escuchar-vinculadas con determinados espacios- que sería necesario revisar o poner en consideración. Haciendo referencia a una oposición entre "las unas y las otras»: las unas (como aquellas establecidas, prescritas, autorizadas o dominantes) y las otras (que buscan escapar de esa dominación, prescripción o autorización, que configuran otras posibilidades).

5 Lang (2020), aborda la idea de volver disponible al trabajar la noción de "dar a oír» (siguiendo a Graciela Frigerio en torno a la idea de dar o donar en la educación) que abordaremos en profundidad más adelante. 
Acercándonos al sitio al que queremos llegar: ¿a qué otro tipo de propuestas podríamos dar lugar entre las escuchas y el disfrute? Para comenzar a abrir este interrogante les compartimos una idea de Lawrence Kramer (20II), quien comienza a enlazar estos dos elementos presentados en el binomio: escuchar y disfrutar. El autor señala lo siguiente:

El placer de escuchar música se aleja considerablemente a entender la música como una cadena de intervalos, o como un conjunto de grupos rítmicos, o como una sucesión de acordes que se nos presentan para que los categoricemos si pretendemos dilucidar su sentido. Por el contrario, al participar de la música en la búsqueda de regocijo estético, es precisamente el placer que experimentamos lo que nos impulsa a tratar de entenderla (en Burcet y Jacquier, 20I2:I2).

Placer, disfrute y goce, algunas de las palabras que pensamos para este primer binomio, parecen estar conectadas de alguna manera. Además, trascienden el lenguaje mismo de este texto para convertirse en gemas preciosas capaces de descifrar claves de enseñanza poderosa. Así, el disfrute irrumpe como espacio o estadio potencial de gozo y regocijo, que se inscribe en una experiencia artística placentera. Podríamos imaginar, entonces, experiencias artístico-musicales necesariamente vinculadas al placer, cuestión que aparece en las voces de las entrevistadas como un punto en el que es necesario detenerse a pensar y que se presenta, en gran medida, cargado de incertidumbre y no menos desafíos para el enseñar.

Demos voz a algunas de esas inquietudes, por ejemplo: ¿cómo organizar una experiencia de escucha desde el disfrute? ¿Cómo se da lugar al mismo en la educación? En vista de esas cuestiones, resulta fundamental potenciar nuevamente la mención del regocijo estético en la cita anterior. Sostenemos que es a partir de su inclusión que aparecen diversas formas a través de las que la música puede manifestarse, hacerse, comprenderse y redimensionarse en y hacia nuevas escuchas, dando lugar a múltiples experiencias vivenciales, afectivas y emotivas que potencian (y se potencian en) ese acto de conocer. 
Así, desde esos modos de participar de la música como regocijo estético, nos preguntamos: ¿qué entendemos por escuchas vinculadas al disfrute, a partir de las músicas que ofrecemos o ponemos a disposición? Posibles respuestas se encuentran en las expresiones de las docentes, recuperadas desde sus vivencias, ya sea por evidenciarse contacto o distancia con escuchas en clave de disfrute. Algunas de ellas aparecen enunciadas como:

Después en la facultad uno pierde eso de escuchar por el placer de escuchar y nada más [...] Cuando empecé la facultad terminó todo el disfrute pleno de no pensar en nada técnico o musical. No hubo vuelta atrás. [...] una vez que ingresas a la carrera esa escucha se hace más reducida a lo técnico (entrevistada II)

Cuando entré a la carrera, fue otra cosa... [...] Yo pasé de hacer un montón de cosas a tener una formación académica que no tuvo nada que ver con el juego, con la exploración, con la libertad, sino que entré en un sistema de formación (entrevistada III)

Si expresiones como estas fueron motivo de sorpresa en las entrevistas, al profundizar el análisis comenzaron a alertarnos. Son recurrentes las referencias a las limitaciones que van cercando el placer por escuchar y que se apoderan de determinados espacios institucionales. Sin lugar a dudas, un estatus canónico que debemos desactivar en la formación académica es aquel que dispone una escucha reducida únicamente a «lo técnico».

Y es que: ¿̇no es acaso el espacio de la formación docente aquel que debería expandir lugares, espacios, conocimientos e instancias, en lugar de reducirlos, cerrarlos, limitarlos? Ese disfrute, en cambio, se presenta muchas veces como un elemento apartado, disociado, escindido de la formación docente. Hablamos de un aspecto silenciado que debería reconsiderarse en relación con los desempeños que el futuro profesional necesitaría en sus prácticas áulicas, que implican al juego, la exploración y la 
libertad tanto como al disfrute en el acercamiento hacia las músicas y en la interacción con los estudiantes al participar de las mismas.

Pero ¿por qué recuperar estas experiencias personales, relacionadas con la formación de las docentes entrevistadas? ¿Qué vinculación pueden tener con algo de lo que sucede en las aulas de los IFD? En relación con estas preguntas, nos inquietan otras como: ¿̇e replican aquellas experiencias que escindieron disfrute y escucha en el acercamiento personal con la música? ¿Cómo ofrecemos experiencias que potencien el disfrute y cuánto de él estamos dispuestos a habilitar?

Afortunadamente, algunos aportes pueden ayudarnos a desocultar algunos aspectos y a construir un campo de posibilidades que hagan frente a esas indagaciones. Compartimos las poderosas palabras de Lang quien, en sintonía con la noción de musicar (musicking), nos invita a imaginar la posible vinculación de múltiples dimensiones en torno a la escucha (entre ellas el disfrute) en el gesto de «dar a oír», un gesto que implicaría, para el docente, un volver disponible o una acción de ofrecer:

Dar a oír concierne al gesto político de distribuir (esto es ex-poner, acercar, volver disponible) una serie de instancias que favorezcan experiencias vinculadas al conocimiento, entendimiento, comprensión y (quizás) disfrute de la herencia cultural, artística y musical en la que chicas, chicos, y estudiantes puedan tomar y ser parte (Lang, 2020: II4).

Es importante destacar que la reflexión en torno a lo que ofrecemos atiende tanto a qué músicas como a través de qué instancias se ofrecen las mismas 6 . Se trata, entonces, de agudizar el foco de atención tanto sobre las músicas que seleccionamos como sobre aquellas prácticas que habilitamos en relación a cualquier música. Traemos esto a cuento porque, al conversar sobre ello con las entrevistadas, la discusión parecía rondar recurrentemente alrededor de qué ejemplos musicales se llevan a las

6 En relación con el "dar a oír", podemos imaginar, por ejemplo, cómo diversidad de músicas posiblemente desconocidas, lejanas o poco frecuentadas por los estudiantes pueden volverse disponibles desde el disfrute, habilitando también la participación en diversas formas de hacer música o de musicar (escuchar, cantar, ejecutar, crear, imaginar, fantasear, entre otras). 
aulas de los IFD y, sobre todo, en sus géneros, dejándose de lado muchas de las otras implicancias que acoge el gesto de «dar a oír».

Sostenemos entonces -y esta es una idea que defendemos con gran devoción- que como docentes de música no ofrecemos solamente objetos artísticos, sino también instancias, prácticas, momento e incluso usos ${ }^{7}$ a través de los cuáles vincularse con esos objetos -las músicas, en este caso-. Siguiendo nuevamente a Lang, se trata de volver disponible para un otro ciertos bienes y prácticas culturales y artísticas (Lang, 20I9: I60). Insistimos: no solo ofrecemos objetos artísticos, sino momentos vivibles, espacios creativos a través de los cuales participar de la música, tiempos para trabajar la estesis ${ }^{8}$, momentos cargados de disfrute, de gozo, de placer.

Proponemos, no con menos insistencia, considerar el vínculo entre músicas, escucha y disfrute no solo teniendo en mente a nuestros estudiantes, sino también la propia artesanía del ser docente y hacer docencia $^{9}$. Creemos en la fuerza de estas provocaciones para pensar alternativas, para no conformarse, para seguir indagando, para ofrecer al futuro profesional docente en formación y para cultivar estos gestos desde la enseñanza. Tener en consideración estos aspectos es una invitación a disponer y arreglar (con delicadeza, amor e inteligencia) un aula en el que podamos conectarnos con la música de otras maneras, favoreciendo escuchas interesantes, placenteras, llenas de disfrute.

Reconocemos, sin embargo, que el entretejido que se establece entre esas escuchas y las decisiones didácticas que las habilitan, da cuenta de un entramado de vínculos diversos y complejos que se despliegan particularmente en la construcción metodológica de cada clase. Sabemos que se trata de un terreno con muchos riesgos y pocas garantías. Pero, como veremos en el próximo binomio, el riesgo se configura como un espacio de oportunidad para atreverse a explorar.

7 «Uso tiene que ver con la capacidad productiva de los 'receptores' de darle a la música una significación relativa a sus intereses y deseos anclados en trayectorias sociales que los dotan de recursos específicos para esos ejercicios de producción simbólica con los que símbolos se reciben" (Semán, 2019: 12).

8 Entendida como «la sensibilidad o condición de abertura, permeabilidad o porosidad del sujeto al contexto en que está inmerso" (Mandoki, 2006: 50).

9 Recuperamos, desde la voz de Sennett, el sentido de artesanía como: "el deseo de realizar bien una tarea, sin más" (2009: 20). El autor nos invita a realizarla, atendiendo a las cualidades de los elementos que dispone el artesano y los modos concretos y particulares de hacerla. 
Por eso, para dar cierre a este binomio, no queremos dejar de extender estas invitaciones para que el disfrute pueda ocurrir, transformar, irrumpir, invadir, mover y conmover desde las prácticas áulicas. Pensar una clase, seleccionar las músicas, ofrecer escuchas, supone además considerar los gestos que las habilitan, las decisiones que las moldean y las formas que hacen posibles enseñanzas potentes.

¿Qué imaginan los lectores cuando decimos lo plegado, lo implicado? ¿Qué imágenes sinuosas o escurridizas evocan estas palabras? Pliegue e implicación son de hecho términos íntimamente relacionados. A través del análisis de Manero Brito sobre la palabra «implicación», podemos reparar en que el prefijo «in» refiere algo hacia adentro, que el verbo latino «plicare» significa, precisamente, doblar o plegar, y que la terminación «ción» nos remite más a un movimiento que a un estado. Implicación, entonces, a través de esta imagen movediza a la que nos invita el autor, «nos plantea algo que está siendo doblado hacia adentro, estableciendo pliegues» (Manero Brito, I997: III).

El mismo señala además que la implicación alude a «una situación plegada en sí, pero plegada también en el sujeto mismo de conocimiento» (Manero Brito, 1997: II2), por lo que sujeto y objeto se encuentran ambos implicados en una misma situación. Este último aporte no es menos importante si consideramos que, a través de un acercamiento -desde sus relatos- a los sujetos (las docentes, en este caso) implicados en las prácticas pedagógico-musicales, podremos llegar a construir conocimiento acerca de estas últimas ${ }^{10}$.

Recapitulando la idea de Sennett, entonces, en este desvelar, en este descubrir o manifestar un territorio nuevo, lo plegado no buscará ser des-plegado o lo implicado ser ex-plicado. Por el contrario, pondremos en marcha nuestra labor interpretativa sobre los pliegues mismos, sobre

10 Estudiar acerca de los sentidos construidos sobre la Educación Musical en la formación docente permite conocer acerca de posibles capacidades profesionales adquiridas y potenciales de ser desarrolladas por los estudiantes del Profesorado de Música del Instituto Superior de Música de la Universidad Nacional del Litoral. Dichos aportes serán retomados dentro de la investigación en el marco del Programa de Promoción y Apoyo a la Investigación en Temas de Interés Institucional - PAITI Arte - Convocatoria 2019, del que forman parte los autores. Esta vinculación tiene también directa incidencia en el análisis de las trayectorias de los estudiantes y sus desempeños en el marco de las cátedras de Prácticas de la Educación Musical y Didáctica de la Educación Musical, que abordan la enseñanza en el Nivel Superior. 
la implicación de las docentes con sus prácticas. Desde allí, como artesanos, intentaremos tejer, a partir de esos «hilos», un nuevo relato (incluyendo destejer y retejer).

Tenemos la certeza de que mucho de lo que emerge en esos pliegues configura potentes aportes para pensar nuevas posibilidades en la enseñanza de la música. Sin más, entonces, abrimos paso al primer binomio.

\section{$2 \cdot$ Arriesgar - Desarmar}

En el fondo, la libertad como hazaña creadora de los seres humanos, como aventura, como experiencia de riesgo y de creación, tiene mucho que ver con la relación entre lo que heredamos y lo que adquirimos [...]

Lo que no es posible, sin embargo, en este esfuerzo por la superación de ciertas herencias culturales, que repitiéndose de generación en generación a veces dan la impresión de petrificarse, es dejar de considerar su existencia

Freire, 1993:II7-II8

"Hacer una clase que no la hizo nadie tiene sus riesgos...", expresa firmemente la entrevistada I. Recordamos haber sido cautivados ante la potencia que esta frase nos ofrecía, ya en el momento de las entrevistas. A partir de ese mismo impulso, que alienta a hackear nuestros pensamientos, proponemos desandar este binomio.

Comencemos entonces con una pregunta: ¿cómo pensar y llevar a cabo propuestas arriesgadas, que enciendan nuevas chispas y aviven la intuición sobre una buena clase? En la voz de la entrevistada I aparecen algunas claves a partir de las cuales trazar una respuesta: «[hay que] trabajar desde la curiosidad, la pasión. Esos son motores fundamentales. [Hay que] desacartonar un poco la estructura de una clase formal», expresa, convenciéndonos de que definitivamente estamos ante algo cautivador. Sin embargo, se desprenden algunas otras inquietudes: ¡cuáles son esos rasgos "formales» que necesitan revisarse o "desacartonarse»? ¿Qué vínculo se establece con aquello heredado, recuperando la cita de 
Freire del comienzo, que conserva su lugar hegemónico en las prácticas de educación musical?

Algunos otros fragmentos aparecen en sintonía con estas preguntas. La entrevistada II, por ejemplo, señala lo siguiente: «no es culpa nuestra, que nosotros somos malos docentes, sino que estamos tan formados... [la cuestión] es deformar un poco de eso». La misma docente complementa esta idea señalando que se trata de «deformar [...] y escuchar...». ¿ $\mathrm{Se}$ estará refiriendo aquí a la escucha como observación o atención, como parte de un prueba y error? ¿Serán el «deformar» y «escuchar» elementos clave de esas prácticas arriesgadas, que desacartonan las «formalidades»?

Pareciera que algo del resquebrajamiento de lo rutinario, del contrasentido ante lo previsto, de lo de-formante ante lo instituido, entra en juego aguerridamente al enseñar. Por todo esto, podríamos preguntar también: ¿existe algo en esa formación que impide deformar algunas lógicas? ¿Sobre qué aspectos sería deseable trabajar en la formación docente -y en la enseñanza musical en general- para dar lugar a eso arriesgado?

No queremos continuar sin hacer otros interrogantes fundamentales, a saber: ¿qué es lo arriesgado? ¿Qué conlleva una práctica arriesgada y qué la distingue de otras? Para reflexionar sobre estas preguntas, recuperamos a Alliaud en su libro Los artesanos de la enseñanza, fuertemente vinculado con las ideas de Sennett, quien nos invita a pensar lo siguiente: «enseñar hoy es ante todo crear, inventar, salirse del guión o del libreto. Probar y ser puesto a prueba en cada circunstancia; considerando la enseñanza como artesanía» (Alliaud, 20I7: 35). Algo de esto se hace visible en las palabras de la entrevistada I, cuando propone «animarse al cambio y al "desarme" de la postura del docente».

En este punto, quizás el arriesgar esté en sintonía con la labor de un artesano, de idear, descomponer y reinventar de manera original. Aún más se evidencia esa afinidad si recuperamos las palabras de Sennett expuestas en la introducción: «en la mente del artesano, la solución y el descubrimiento de problemas están íntimamente relacionados» (Sennet, 2009: 23).

Para profundizar más en ello, según el mismo autor «todo buen artesano mantiene un diálogo entre unas prácticas concretas y el pensa- 
miento». A su vez, sugiere entender la labor del mismo, en su relación con las artesanías, como "maneras de utilizar herramientas, organizar movimientos corporales y reflexionar acerca de los materiales» (Sennet, 2009: I2). Podríamos proponer, entonces, que un profesor artesano da lugar a lo diverso, lo alternativo y lo reflexivo sobre los materiales y sus usos. Nos atrevemos a sostener que algo de todo esto tiene que ver con esas prácticas arriesgadas.

Sin embargo, no queremos extendernos en disquisiciones teóricas. Quizás la siguiente cita, extendida como una invitación que seduce y que aparece en voz de la entrevistada II, pueda ayudarnos a visualizar algunas de estas ideas:

[Trato de] incorporar diversos aspectos de los modos que tiene enseñar música y en relación al modo de priorizar lo corporal-local y después ir al instrumento, el modo a trabajar en particular desde lo que trae la persona y no solamente en torno al sistema de notación universal. Y entonces, el «meterme» en eso me está dando más fundamento para mis prácticas. (Entrevistada II)

Creemos que en este fragmento se evidencia un gran arriesgarse (que ocurre como construcción artesanal de la enseńanza) cuando esta docente señala los diversos aportes metodológicos y artístico-musicales de los que se nutre (en referencia previa a la formación-¿ideformación?paralela que realiza y que pone en juego entrenamiento corporal, educación somática, terapia no verbal, discapacidad, entre otros). Todo lo dicho daría lugar a «meterse» (o implicarse) de una manera más comprometida con los estudiantes y con la enseñanza misma.

Ahora bien, para ensayar otras respuestas sería importante considerar: ¿cómo pensar la Educación Musical en clave de acontecimiento, ${ }^{11}$ dando lugar al riesgo? ¿Cómo irrumpir artesanalmente en la enseñanza de la música?

11 En referencia a los "actos impredecibles, o impensados, y ante los que debemos estar atentos, ya que irrumpen bajo la figura de acontecimientos" (Bárcena, 2002: 40). 
En relación con esto, no está de más recuperar nuevamente lo dicho por la entrevistada I, a saber: "[hay que] trabajar desde la curiosidad, la pasión. Esos son motores fundamentales». La entrevistada III, por su parte, expresa lo siguiente: «me parece que la música tiene que inspirar, tiene que reconfortar el alma, tiene que hacer que uno disfrute». Hacemos énfasis en ese uno pensando en esa implicación y compromiso que el docente debe tener con lo que ofrece y con las prácticas que lleva a cabo, y que vinculamos con esa pasión y curiosidad del primer fragmento. Todos ellos, sostenemos, son elementos fundamentales para llevar a cabo prácticas arriesgadas.

Por otro lado, en otras expresiones, emerge la intención de habilitar nuevos encuentros con la música, asumida como una tarea arriesgada que acoja y permita, en el acontecimiento «la posibilidad del error o la equivocación» (entrevistada III). En resonancia con esto, la entrevistada I, enuncia: "[hay que] tratar de innovar a pesar de los riesgos, ya sea en las actividades o si tengo la responsabilidad de llevar adelante algo. Y, me la juego. [Hay que] romper estereotipos, despertar en el otro, probar, incursionar, innovar, errar, equivocarse».

Esto dicho se presenta como evidencia del ir más allá, del cambio, de la transformación posible, de jugarse por aquello que no parece permitido, que abre otros caminos y que desafía a la búsqueda de otros sentidos. En estas instancias, la flexibilidad ante lo diverso que cada docente pueda desarrollar tendrá un rol crucial. Sin lugar a dudas, es la actitud de receptividad y atención ante lo imprevisto (de escucha, podríamos decir nuevamente) lo que determinará la fluidez con que ponga en juego cada una de esas posibilidades.

Una última interpelación da cuenta de otros aspectos que irrumpen en clave de lo arriesgado. Esta se reconoce, por ejemplo, en la siguiente frase: «yo planteo una consigna que no tiene una respuesta. Es un ir construyendo» (entrevistada II). Al respecto, recuperamos las palabras de Larrosa (20I8), quien expresa que un profesor propone un camino y también dispone de una manera particular de ponerse en movimiento en el mismo. Se trata, entonces, de un abanico de posibilidades desde lo diverso, lo múltiple, lo creativo y lo distintivo, que el docente dispone y 
que son particularmente configuradas por los actores de dicha relación educativa. Queda expuesto, así, lo que tiene de impredecible el acontecimiento educativo, a lo que un abordaje desafiante puede dar lugar como espacio de posibilidad.

Para dar un poco más de cuerpo a estas reflexiones, proponemos algunos aspectos atrevidos a los cuales arriesgarse en las prácticas docentes, como por ejemplo: animarse a lo fronterizo o lo no tan explorado en las prácticas áulicas, para salirse de lo rutinario o lo ya experimentado; volver disponibles autores y artistas de diversos campos disciplinares; dar crédito a esos pensamientos creativos del docente que surgen de sus exploraciones y búsquedas en relación con la música, el arte y la cultura; recuperar escuchas y dar lugar a propuestas sugeridas por los estudiantes; estar atentos a producciones musicales, artísticas y literarias que irrumpen en la cotidianeidad: publicaciones, grabaciones, conciertos, ediciones, exposiciones; estar pendientes de posibles discusiones que se dan en el campo de lo artístico y de lo ideológico (para dar un ejemplo: cómo las discusiones en torno al género o las perspectivas decoloniales repercuten en las formas de producir y consumir arte en general y música en particular y de construir conocimiento sobre las mismas), y que afectan de manera crítica la formación; entre otros.

Pero vayamos un poco más allá: ¿podría considerarse ese arriesgar como una acción implicada con un posible desarmar? Sobre esa conexión, que consideramos fundamental y que compone este binomio, podemos construir otros sentidos poderosos.

Creemos que desarmar se relaciona con las diversas posibilidades de mirar lo acontecido y, desde allí, impulsar nuevas búsquedas y cambios. Veamos algunos ejemplos: la entrevistada i señala la importancia de «poder ir hacia atrás [...], revisar». Más adelante, menciona lo siguiente, en relación a un proyecto de varias clases desarrollado con sus alumnas: «...cuando vieron el resultado final 'fueron para atrás' y vieron todo ese proceso, cómo arrancaron, con la idea principal con la que arrancaron, y cómo terminaron. Y eso las hacía relacionar con las otras materias...». Es decir, se da lugar a la reflexión compartida, que potencia el lugar de las preguntas, el análisis y el intercambio colectivo junto a los estudian- 
tes. Estos aspectos, vinculados a la revisión crítica y a posibilidades de mejora, cambio o transformación, constituyen ese desarmar, que obra junto a ese arriesgar.

Por todo esto, afirmamos que en los devenires y decisiones en torno al Arriesgar-Desarmar, se hilvanan nuevas formas del oficio de profesor que tienen que ver con habilitar el riesgo como espacio de oportunidad y posibilidad, y con el trabajo reflexivo sobre esas prácticas arriesgadas. Se trata entonces de arriesgar para dar lugar a otras formas posibles («una clase que no la hizo nadie»), y de desarmar, como artesanos, las propias prácticas (recuperando nuevamente la idea de tejer, destejer y retejer de la introducción).

Ambos procesos conllevan una implicación artística y docente desde la interdisciplinariedad (entre otras dimensiones potentes) que ofrece el formato taller en estos espacios curriculares, posibles de replicarse en diversas enseñanzas musicales. Además, parecen girar en torno a la multiplicidad y variedad de experiencias artísticas, donde lo singular y lo colectivo están implicados en una dinámica creativa de intercambios incesantes.

Para finalizar, los vínculos que en esa dinámica se juegan posibilitan otros aspectos atrevidos en la enseñanza, punto en el que se entretejen asuntos que profundizaremos en el último binomio.

\section{$3 \cdot$ Convivir - vincular}

El saber no es concebido como una mera actividad intelectual, sino que ampliamos nuestros modos de ser afectados para avanzar hacia una perspectiva multidimensional de la experiencia capaz de albergar tanto a la razón y la lógica como a las emociones y la sensibilidad

Najmanovich, 2017: 25

Sin lugar a dudas, es convivir la palabra de este tercer binomio cuya inclusión más postergamos y sobre la que más reflexionamos. ¿Será que este aspecto se siente poco valorado y por eso dudamos si trabajar sobre el mismo generaría nuevos sentidos a construir dentro de la enseñanza? O 
más bien, ¿`será que este convivir apareció en los relatos muy tímidamente mencionado, con sentidos y sinsentidos desde nuestra interpretación?

En efecto, se trata de un aspecto que se vislumbró muy solapadamente (de manera opaca, borrosa, imprecisa) pero no con poca frecuencia en las voces de las entrevistadas. $Y$ es que, si bien se trata de una dimensión poderosa de la enseñanza, constituye también un lugar paradojal, que aloja sentidos y sinsentidos necesarios de ser considerados. Proponemos, entonces, trabajarlo alejándolo de lo dogmático, de lo prescriptivo, de lo que podría atarlo al buen sentido o al sentido común, para considerarlo un aspecto clave y a desvelar en el desarrollo y transformación de prácticas de enseñanza musical al presente.

Para dar inicio, es imposible no vincular el convivir que compone este binomio con la obra El Convivio de Dante. Ese convivio, entendido como «banquete» (o "banquete educativo», en este caso), es considerado una invitación, un encuentro, una reunión con y hacia todos. Es un espacio donde existe algo más que la simple disponibilidad de estar juntos, para volverlo lugar de encuentro y de conocimiento que se ofrece y comparte; espacio donde los vínculos y las relaciones que se generan entraman espacios de actores y de espectadores.

Es entonces el convivir lo que nos convoca para entretejer algo de lo humano y lo vincular en relación con la enseńanza. Abramos paso a algunos interrogantes que puedan servirnos para desandar este binomio: ¿qué nuevos sentidos podríamos construir en torno a lo humano, lo afectivo y lo relacional que se juega en el convivir? ¿De qué manera la enseñanza de la música podría contemplar esos aspectos? ¿Qué relevancia poseen estos saberes dentro de las currículas? ¿Existen espacios para su construcción y abordaje?

Creemos que, dentro de muchas propuestas pedagógico-musicales -como cantar junto a otros, concertar una ejecución, interpretar instrumentos en grupo-, se pone en juego mucho del convivir. Sin embargo, muchas veces aparece como un aspecto librado al azar, poco sistematizado, sin reconocerse plenamente la potencia que en la convivencia se juega. Recuperemos, entonces, algunos aportes que nos permitan acercarnos de manera más reflexiva al mismo. 
Abordemos aquellas relaciones entre docentes y estudiantes que posibilitan el nexo con los saberes artísticos y musicales y que se instalan dentro del convivir. Al respecto, Souto propone la idea de «una ligazón en el encuentro" que se favorece desde los vínculos «con otros, entre nosotros mismos, y con la formación [...] donde el sujeto crea otros sentidos como composiciones nuevas» (Souto, 2016: 247). En sintonía con esto, Najmanovich hace mención de un encuentro en el cual «todos los seres estamos conectados en una infinita trama vincular de la que somos partícipes» (Najmanovich, 2019: 42). Por lo dicho hasta aquí, la concepción de encuentro y afectación, de trama siempre compleja y cambiante, da lugar a modos diversos de construir sentido sobre la condición humana, siempre móvil y multidimensional.

Creemos que algo de esto se ve reflejado en las voces de las docentes. La entrevistada II, por ejemplo, menciona lo siguiente: «no es que si yo le pongo una música a alguien esta música va a generar... ¡No! Si mi vínculo previo o posterior a hacer esa música no lo genera, no funciona». Es verdaderamente cautivante la propuesta de un trabajo que necesariamente debe darse desde el vinculo, y que posibilita el hacer musical. A partir de allí, insistimos en la idea de que la música, por sí misma, no garantiza el encuentro con los saberes. Es el vínculo el que, en parte, los habilita y les da lugar.

En palabras de la entrevistada I podemos recabar otras reflexiones interesantes, como la siguiente: «es fundamental el diálogo con las alumnas, la empatía, por más que sean muchas [...] abrir el espacio para que circule la palabra». Se trata de lazos que forman parte de un tejido vincular dinámico que gira en torno a lo emocional, lo sensible, lo dialogal, y lo afectivo de las relaciones y los encuentros. Así, la condición humana, en el acto de conocer, se manifiesta como configuración situada, que crea y fortalece lazos múltiples y que potencia los encuentros de cuerpos concretos y únicos, que conviven en espacios de acercamientos con la música, el arte y la cultura.

En este punto, recuperemos nuevamente los aportes de Souto, ahora para comprender, desde la lógica del «doble cauce», la construcción de 
saberes musicales y artísticos. Este doble cauce refiere a una doble implicación entre lo cognitivo-epistémico de los saberes, por un lado, y el componente emocional que se establece en el vínculo con ese saber, por el otro (Souto, 2019:34). En completa sintonía, en voz de la entrevistada II, se expresa lo siguiente:

Mi placer estaba cuando había alguien, cuando yo tenía alguien a quién escuchar, y a quién o con quién generar un vinculo sonoro. Después, con el tiempo, me di cuenta que esa otra persona me importaba más que lo sonoro, entonces ahí es cuando yo empiezo a adentrarme en lo que es «el otro diferente». (Entrevistada II)

Es imposible no sentirse cautivados ante esta cita, que recupera algo valioso acerca de la implicación de cada uno de los actores en la práctica musical dentro de la grupalidad, como rasgo característico del convivir. Se trata de una implicación con el otro o los otros, que se profundiza a través del con-versar desde las músicas. El con-versar es entendido aquí en sintonía con el con-vivir y, siguiendo a Najmanovich (2020), se vincula con la conversación de cuerpos presentes que entrelazan vidas y cuerpos vivos, no mentes abstractas.

Pensar la enseńanza de la música en un sentido humano y vincular pone entonces de manifiesto la importancia de redimensionar la humanidad de todo sujeto partícipe del acontecimiento educativo. Al respecto, Musumeci propone una educación adecuada "para todo ser humano, y a la vez para cada ser humano en su totalidad» (Musumeci, 2002: I). Se trata de un enfoque que considera rasgos de una educación musical «humanamente compatible», en la que las situaciones de aprendizaje comienzan desde la convicción de que cada persona tiene vastas capacidades para desarrollarse y aprender, y cuyos «estados sensitivos, afectivos, emotivos y emocionales están fundacionalmente interrelacionados con toda cognición» (Thurman, 200I en Musumeci, 2002: I).

Entonces, «¿cómo generás un vínculo para que el otro pueda disfrutar de tu hacer docente? Si no generás un vínculo, no existe», expresa la entrevistada II. Esto nos conduce directamente a replantearnos: ¿cómo 
la educación musical habilita estos encuentros y nuevas formas de alojar lo vincular? ¿Cómo proponer instancias que, involucrando lo vincular como potencia, favorezcan los encuentros con el conocimiento artístico-musical? En relación con esto, y como forma de habilitar nuevas formas de vincularnos, compartimos una cita de Najmanovich, quien señala lo siguiente:

Ya no hay un sujeto opuesto a un objeto, sino un universo de interacciones e intercambios que, en el campo de las relaciones humanas, nos lleva a pensar que una persona, un grupo, una institución, no «son» sino que advienen y devienen en y por los intercambios en los que participan. (Najmanovich, 2019: 58)

Pensemos entonces en diversas tramas desde lo vincular (y dentro del convivir) que focalicen sobre los vínculos, las relaciones que se tejen, los modos en que somos afectados y cómo afectamos a los demás en el marco de las mismas.

Por último, creemos que los sentidos del vincular irrumpen en el devenir educativo y se constituyen como transformación de lo posible y desde lo disponible, sin caminos únicos o determinados previamente. Lo vincular, lo humano, lo relacional, al ser considerados como aspectos en devenir, son tensionados ante un tiempo futuro que aguarda ser transitado, que no se conoce, que es imposible proyectar. Lo que deviene, deviene no de aquello a ser conocido, sino de aquello que se recorre, y da lugar al sentido como efecto producido de esas instancias recorridas.

Por todo esto, tramar lo vincular como aspecto en constante construcción implica un trabajo de artesanato en la educación que da lugar a lo que acontece, a lo latente, a lo situado, como así también al excluido, al no conocedor, al otro en su vasta otredad y diversidad. 


\section{Un ÚLTIMO DESVELO}

Nos acercamos hacia el final de este escrito. Habrán percibido los lectores que a lo largo del mismo aparecieron varios interrogantes que dan lugar a seguir la conversación, desde el análisis y la lectura y relectura de cada situación educativa en particular. Deseamos que, al acercarse a esta tarea de desvelar algunos aspectos de las prácticas de Educación Musical, se sientan partícipes de seguir construyendo sentidos, cada día, en cada práctica, en cada espacio donde acontezca lo educativo y lo musical. Es nuestra intención que, para todos aquellos que atravesaron este artículo (profesores o estudiantes de música, de otros lenguajes artísticos, de la formación docente o de otras posibles disciplinas y especialidades), lo aquí presentado pueda inspirar y aportar un aire renovador en relación con sus clases.

Por otro lado, por los sentidos que adquieren los relatos de algunas experiencias y el trabajo artesanal de interpretarlos y de tejer a partir de ellos, esperamos que lo abordado en este escrito pueda impulsarlos a poner manos y cabezas en marcha en sus propias prácticas, tanto como a construir sus propios relatos. Deseamos, además, que se hayan sentido interpelados y conmovidos, tal como nos sucedió al conversar con las entrevistadas, quienes nos regalaron poderosas resonancias y a las cuales manifestamos especial gratitud. Así, aspiramos a que cada enseñanza musical pueda, desde sus pliegues, regalarles (y regalar a sus estudiantes) sus sellos distintivos, su quehacer identitario en el oficio, como una particular forma de vida y de devenir en ella.

Para cerrar, decidimos compartir algunas palabras de Marta Souto y contagiarles, desde esta cita, su impulso renovador: «la formación docente es transformación en el sujeto docente [...], pertenece como el sentido mismo al devenir y al avanzar» (20I6: 249). Apostemos entonces, a habilitar profundas transformaciones; transformaciones artesanales que supongan una apertura al escuchar sin dejar de lado el disfrute, que den lugar al riesgo y a la posibilidad de desarmar en las clases, y que recuperen los lazos del vincular como trama necesaria del convivir. 


\section{REFERENCIAS BIBLIOGRÁFICAS}

ALIGHIERI, DANTE (1304-1307): El convivio, Madrid, Ed. Espasa-Calpe.

Traducción: Cipriano de Rivas Cherif (1919).

ALLIAUd, ANDREA (2017): Los artesanos de la enseñanza. Acerca de la formación de maestros con oficio, Buenos Aires, Paidós.

BÁRCENA, FERNANDO (2002): «El aprendizaje del Comienzo. Variaciones sobre la Educación, la Creación y el Acontecimiento» en «Revista Educación y Educadores" Vol. 5. Recuperado de: http://educacionyeducadores.unisabana. edu.co/index.php/eye/article/view/510 (consultado en enero de 2020)

BURCET, MARÍA I., JACQUIER, MARÍA Y OTROS (2012): Educación Auditiva. Práctica y desarrollo de habilidades de audición y transcripción musical Primera parte, La Plata, SACCoM Ed. UNLP.

DAVIDSON, LYLE Y SCRIPP, LARRY (1992): "Surveying the coordinates of cognitive skills in music. Estudio de las habilidades cognitivas en Música» en Colwell, R. (ed.) Handbook of research on music teaching and learning, Chapter 25: 392413. New York, USA, Shimer Books.

FREIRE, PAULO (1993): Cartas a quien pretende enseñar, Buenos Aires (2002), Siglo XXI.

LANG, PABLO (2019): "Dar a oír. Notas a favor de una educación estética (y artística) en la formación docente» en Dieciséis, Revista del Instituto Superior del Profesorado $N^{\circ} 16$ "Dr. Bernardo Houssay", Rosario, Laborde editor.

(2020): En el nombre de la Música: problemas entre música, enseñanza y escuela, Santa Fe, Ediciones UNL.

LARRosa, JORge (2018): P de profesor, Buenos Aires, Novedades educativas. MANDOKI, KATYA (2006a): Estética cotidiana y juegos de la cultura. Prosaica I, México, D.F., México, Siglo Veintiuno Editores.

MANERO BRITO, ROBERTO (1997): Multirreferencialidad y conocimiento, Conferencia magistral dictada el 20 de junio de 1997 en la ENEP Iztacala, pp. 101-120, del Segundo Taller sobre Multidisciplina.

MUSUMECI, ORLANDO (2002): Hacia una educación de consenvatorio humanamente compatible, Actas de la II Reunión Anual de SACCoM, La Plata, Ed. UNLP

NAJMANOVICH, DENISE (2017): «El sujeto complejo. La condición humana en la era de la red» en Revista Internacional de Filosofía y Teoría Social - Utopía y Praxis Latinoamericana, Año: 22, n. 78, pp. 25-48 CESA-Fces-Universidad del Zulia, Maracaibo, Venezuela.

(2019): Complejidades del saber, Buenos Aires, Ed. Novedades Educativas. (2020): Gestando otras narrativas para generar nuevos sentidos, Conferencia en el III Coloquio sobre Escritura, Variación Lingüística e 
Interculturalidad, "Nuevas narrativas: de la afabulación universal a los mestizajes situados-implicados", Universidad Federal del Triângulo Mineiro (UFTM)-(Minas Gerais, Brasil, 26/10/2020). Disponible en: https://youtu.be/ Q5d1RcbkHnA (fecha de consulta: enero 2021).

SEMÁN, PABLO (2019): "Prólogo. La canción nunca es la misma», en GILBERT, Abel y LIUT, Martín: Las mil y una vida de las canciones, Buenos Aires, Gourmet Musical. pp.11-24.

SENNETT, RICHARD (1997): El artesano, Barcelona, Anagrama (2009).

souto, marTa (2016): Pliegues de la formación. Sentidos y herramientas para la formación docente, Rosario, Homosapiens.

(2019): "Acerca de la noción de dispositivo en la formación universitaria", en Rev. Educación, Lenguaje y Sociedad E-ISSN 2545-7667 Vol. XVI No 16 pp. 1-16. DOI: http://dx.doi.org/10.19137/els-2019-161602 (fecha de consulta: noviembre 2020) 